\title{
Native or Non-native-speaking Teaching for L2 Pronunciation Teaching?-An Investigation on Their Teaching Effect and Students' Preferences
}

\author{
Ying $\mathrm{Li}^{1}$ \& Gouzhi Zhang ${ }^{2}$ \\ ${ }^{1}$ Foreign Language Schools, Southwest University of Political Science and Law, China \\ ${ }^{2}$ Capital Construction Department, Southwest University of Political Science and Law, China \\ Correspondence: Ying Li, Foreign Language Schools, Southwest University of Political Science and Law, China. \\ E-mail: liying_22@163.com
}

Received: October 26, 2016 Accepted: November 20, 2016 Online Published: November 21, 2016

doi: $10.5539 /$ elt.v9n12p89

URL: http://dx.doi.org/10.5539/elt.v9n12p89

\begin{abstract}
This study investigated L2 leaners' preferences between native-speaking teachers (NST) and non-native-speaking teachers (NNST) as their English pronunciation teacher, and examined the participants' accentedness and comprehensibility in L2-English pronunciation after being taught by a NST and a NNST. The participants were 30 undergraduates who were doing non-English majors at a university in China. They went through 4-month English pronunciation classes. In the first 2 months, they were taught by a NST. From the 3rd to the 4th month, they were taught by a NNST. Their accentedness and comprehensibility of spoken English were tested at the beginning of the programme (pre-test), at the end of the 2nd month (middle test), and at the end of the 4th month (post-test). Information on their evaluation of the NST and NNST as a pronunciation teacher was collected with questionnaires at the end of the experiment. According to the results, (1) compared with that in pre-test, the participants' accentedness and comprehensibility both improved slightly in middle test; (2) compared with that in middle test, the participants received significant improvement both in comprehensibility and accentedness; (3) the majority of the participants prefer a NST to a NNST to be their English pronunciation teacher.
\end{abstract}

Keywords: L2 pronunciation, native-speaking teacher, non-native-speaking teacher

\section{Introduction}

Are native-speaking teachers (NST) better than a non-native-speaking teacher (NNST) in the teaching of a target second language (L2), particularly in the teaching of the L2 pronunciation? This question may lead to a debate on language discrimination against NNST. Despite there is abundant evidence showing that NNST may be as efficient as, or even better than NST in an L2 teaching (Levis, Sonsaat, Link, \& Barriuso, 2016), the authorities of some universities still prefer to hire native speakers as the target language teacher. Few studies investigated this issue from the perspective of the students. This article, therefore, investigated whether the students prefer to be taught by NST or NNST in L2 pronunciation, and compared their learning results after being taught by NST and NNST respectively.

\subsection{Native Speaker or Non-native Speaker?}

The first question we are going to discuss is the definition of a native and non-native speakers of a language. Traditionally, the concept of a native speaker is understood as self-explanatory. As Bloomfield (1993) notes, "The first language a human being learns to speak is his native language; he is a native speaker of this language" (p. 43). In the field of grammar, Chomsky (1965) viewed native speaker as the only reliable source of linguistic data. A native speaker of English, for example, is defined as someone who speaks English as his or her first language (L1), or mother tongue (Medgyes, 2001). At this point, native and non-native speakers are considered to be two distinguished categories. In recent years, however, this view is challenged by the fact that the born-learned language can be replaced by another language acquired later in life, in the circumstance of which the born-learned language could be "no longer useful, no longer generative or creative and therefore no longer "first" (Davies, 1991). It could happen in the cases of immigration or adoption at an early age (Lee, 2005). Moreover, although being criticized by the old-fashioned critical period hypothesis and relevant studies (i e., 
Felix, 1987), even adult L2 learners have been proved to be able to achieve native-like proficiency of a target L2 in many previous studies (Hazan, Sennema, Iba, \& Faulkner, 2005). Many non-native English speakers were found to be able to pass for native speakers of English in different linguistic fields (Piller, 2002). To rule out the controversy on the "nativeness" of an L2 teacher, a native American English speaker who was born and grew up in New York was recruited in the present study.

\subsection{Native-Speaking Teachers Versus Non-Native-Speaking Teachers}

Given that there is a preference over NSTs and NNSTs, the differences between NSTs and NNSTs in their teaching should not be neglected. Medgyes (1994) conducted an empirical study addressing the NST/NNST issue. According to his survey, NSTs were found to be far less strict in correcting the students' errors than NNSTs. This finding is in line with earlier error gravity studies, such as Hughes and Lascaratou (1982). Moreover, NSTs were reported to intend to use more 'real' language with more confidence and to provide more cultural information than NNSTs. Nevertheless, $40.3 \%$ of the respondents indicated that they felt both NSTs and NNSTs were successful in L2-English teaching. The rest of the respondents were evenly split in favor of NSTs and NNSTs $(25 \%$ and $26.4 \%)$. Similarly, $88 \%$ of the respondents (17 TESOL graduate students with teaching experiences) in Brutt-Griffler and Samimy's (1999) study indicated that NSTs seemed to be more confident English users than NNSTs, yet NSTs were reported to be more aware of the students' needs. It might be attributed to the fact that NNSTs do not share the same linguistic background with the L2 students as the NSTs do, thus NNSTs might have difficulties in understanding the needs and problems of the L2 students (Ma, 2012; Rao, 2008). Nevertheless, Brutt-Griffler and Samimy's (1999) reported that most of the respondents (58\%) felt both NSTs and NNSTs were successful in their teaching.

Regarding students' opinions on NSTs and NNSTs in L2 pronunciation teaching, certain factors were found to be of particular significance, such as the teacher's physical appearance of nativeness (Braine, 2005; Golombek \& Jordan, 2005), their skills and confidence at pronunciation teaching (Ma, 2012; Mahboob, 2004; Reves \& Medgyes, 1994), the students' previous experience with NNSTs (Braine, 2005), and most importantly, the teacher's accent (Butler, 2007; Ma, 2012; Moussu, 2006) as well as the students' L2 proficiency level (Madrid \& Canado, 2004; Lasagabaster \& Sierra, 2002).

For instance, Lasagabaster \& Sierra (2002) investigated students' opinions on the preferences of NSTs or NNSTs among 76 undergraduates of different majors. According to the results, those with experience of NSTs displayed stronger preferences of NSTs over NNSTs than those without such experience (mean score: 3.84 vs. 3.33). They also showed an increased preference for NSTs as the educational level rise (primary mean $=3.18$; secondary mean=3.60; university mean=3.91), which is similar to the finding in Madrid and Canado (2004). Lasagabaster \& Sierra (2002) explained this finding by indicating that NSTs and NNSTs as being more suited to different phases in language education. Moreover, the subjects reported a significantly stronger preference for NSTs in the teaching of pronunciation (mean score $=4.15$ ) than other areas (i e., speaking, vocabulary, culture, civilization, listening, reading). It was attributed to the differences between NSTs and NNSTs' teaching styles, such as the NSTs' relative tolerance towards errors. This explanation, however, may suit any areas of L2 teaching rather than only pronunciation. What mentioned in Lasagabaster and Sierra (2002) is that "the students seem happier with NSTs" in pronunciation class. We may speculate that, except teaching styles, the students may have perceived the accent differences between the NSTs and the NNSTs. Consequently, the students prefer to learn from "better models" (Chen, 2008; Gurkan \& Yuksel, 2012; Lasagabaster \& Sierra, 2002). After all, even NNSTs themselves sometimes doubt whether they are adequate models for pronunciation teaching because of L2 accents (Ma, 2012; Golombek \& Jordan, 2005).

Nonetheless, some studies report that students do not necessarily have negative attitudes toward NNSTs with a non-native accent, though they might display more positive attitudes toward teachers with native accents (Moussu \& Llurda, 2008). For example, Levis et al., (2016) investigated the effect of teachers' L1 on ratings of the students' change in L2 accentedness and comprehensibility. The participants went through a 7-week course of L2-English pronunciation taught by either a NST or a NNST. The NNST was a Turkish-speaking teacher with considerably lower rates in both accentedness and comprehensibility than the NST. According to the results, the teachers' native language background did not display a significant effect on the participants' degree of improvement in accentedness or comprehensibility. Nevertheless, the majority of the participants expressed a preference for NST for pronunciation classes, despite they rated the NNST as highly as the NST regarding their teaching performance in the 7-week course. Levis et al. (2016) further examined the supplementary materials from the participants' interviews, and suggested that the participants seemed to believe that being taught by NSTs, they could have greater improvement by "catching" the native speakers' pronunciation just like catching a cold (Levis et al., 2016; LeVelle \& Levis, 2014; Levis, 2015). However, the general results in Levis et al. (2016) 
suggested this view is mistaken, as neither the NST's nor the NNST's class achieved a significant improvement in their comprehensibility or accentedness in L2-Englih pronunciation.

In brief, both NSTs and NNSTs have their advantages in L2 teaching. It is still an open topic regarding the effectiveness of NSTs and NNSTs' in L2 teaching. The present study, therefore, seeks to further investigate this issue and answers the following research questions:

1) To what degree, if any, do the participants' accentedness and comprehensibility in classes taught by an NST and an NNST improved from pretest to posttest?

2) How do the participants evaluate the NST and the NNST as an L2 pronunciation teacher?

\section{Methodology}

To answer the research questions, quantitative and qualitative data was collected. The participants went through a 4-month spoken English class, which was first taught by a NST and then was taught by a NNST. Their' accentedness and comprehensibility in English speaking was tested with a read-aloud task. The participants' preferences of NST or NNST were investigated with a questionnaire.

The participants: To select participants of similar English proficiency levels, an Oxford Quick Placement test was carried out among 102 undergraduates who were doing non-English majors at a University in China. As a result, 56 participants' English proficiency level was intermediate. 30 of them, who reported to have strong motivation in improving their L2-English pronunciation, and had experienced both NST and NNST in their L2-English education prior to the experiment, were finally recruited to join the experiment (age range: 18-23; mean age: $21.36 ; 15$ female, 15 male). They were paid for participation.

The raters and the rating: Three native Americans ( 2 female and 1 male; mean age $=21.4$ years old) were paid to the evaluating job. They were university students who were doing Linguistics for their Bachelor's degree. They reported that they were born and grew up in American, had never been to China, and had very limited chance to be exposed to Chinese or Chinese-accented English. The participants' recordings from the tests were sent to them with drop-off. The raters were asked to rate the participants' pronunciation in the aspects of accentedness and comprehensibility with a 5 -likert scale (for accentedness: $1=$ no foreign accent, $5=$ very strong foreign accent; for comprehensibility: $1=$ no difficulty to be processed, $5=$ very difficult to be processed). They did the rating separately at their own place. The results were sent back to the investigator after being completed. The final results were the average of the raters' evaluations.

The teachers: The NST was a 26-year-old female volunteer teacher working at a university in Chongqing China. She was born and grew up in California. She had been teaching English in China for half a year by the time of the experiment. The NNST was a 31-year-old female university teacher, who was teaching English at the same university as the NST. She was born and grew up in Chongqing China. She studied in America for 6 years since she was 21 years old, and received her Master's degree and Ph.D's degree there. The 3 raters mentioned above were asked to rate the NST and the NNST's accentedness and comprehensibility of spoken English with a 5-likert scale before the experiment (Note 1). Specifically, the NST showed an accentedness rating of 1.09 and a comprehensibility rating of 1 . The NNST's ratings were 1.58 for accentedness and 1.43 for comprehensibility.

The pronunciation class: The participants went through 4-month spoken English class. In the first 2 months, they were taught by the NST. From the $3^{\text {rd }}$ to the $4^{\text {th }}$ month, they were taught by the NNST. Each class met three times a week, 1 hour per class. The teaching materials used in the class were based on a textbook of spoken English used by English majors-College English: Pronunciation. The NST was asked to teach the first 6 units, whereas the NNST was asked to teach the last 6 units of the textbook. They were both asked to focus on accentedness and comprehensibility only and were allowed to design the classroom activities according to their own needs.

A collection of quantitative and qualitative data: The participants' accentedness and comprehensibility were tested 1 day before the class (pre-test), at the end of the $2^{\text {nd }}$ month class (middle test), and at the end of the $4^{\text {th }}$ month class. Specifically, they were asked to do a read aloud task and a semi-schemed interview. In the read aloud task, the participants were asked to read 25 sentences adopted from Munro and Derwing (2006), twice each. In the semi-schemed interview, they were asked questions about their daily life, such as hobbies. It was designed to collect the participants' spontaneous speech. Their production was auditorily recorded with a high-quality recorder (Roland-05, with the settings of 16-bit mono channel and $44.1 \mathrm{KHz}$ ). The recordings were then sent to the 3 raters for evaluation with drop-off.

Qualitative data was collected in terms of questionnaires to collect information about the participants' perception of the NST and NNST's classes using a 5-likert scale. The questionnaires were handed out at the same time the 
posttest was completed.

\section{Results and Discussion}

\subsection{Testing Results}

Table 1. Descriptive data of the participants' accentedness and comprehensibility in the read aloud task in the 3 tests

\begin{tabular}{|c|c|c|c|c|c|c|c|}
\hline & & \multicolumn{3}{|c|}{ Accentedness } & \multicolumn{3}{|c|}{ Comprehensibility } \\
\hline & & Pretest & Middle test & Posttest & Pretest & Middle test & Posttest \\
\hline $\mathrm{N}$ & Valid & 30 & 30 & 30 & 30 & 30 & 30 \\
\hline Mean & & 3.60 & 3.53 & 3.36 & 3.40 & 3.36 & 3.20 \\
\hline Std. Deviation & & 0.40 & 0.36 & 0.39 & 0.37 & 0.39 & 0.43 \\
\hline Minimum & & 2.89 & 2.70 & 2.70 & 2.45 & 2.42 & 2.06 \\
\hline Maximum & & 4.23 & 4.18 & 4.01 & 4.09 & 4.10 & 4.00 \\
\hline
\end{tabular}

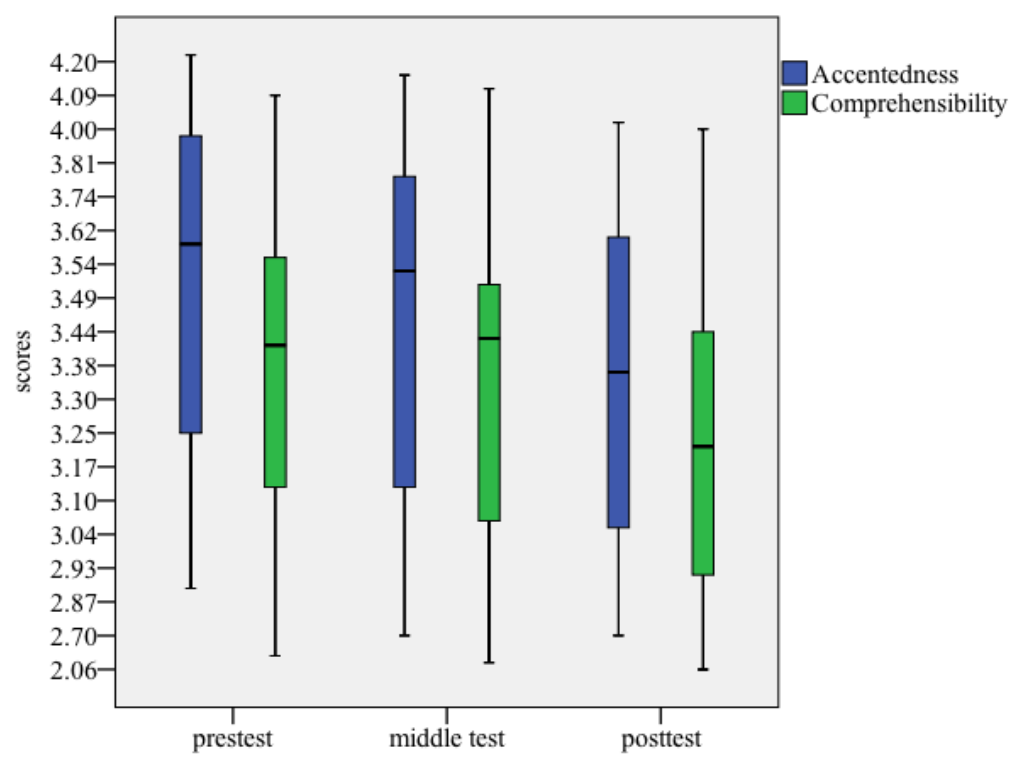

Figure 1. Boxplots of the participants' accentedness and comprehensibility in the read aloud task in the 3 tests

Table 1 and Figure 1 show us the participants' testing results from read aloud task. According to the data, compared with that in the pretest, the participants displayed some degrees of improvement accentedness and comprehensibility in the middle test and the posttest. Specifically, their mean scores of foreign accent decreased from 3.60 in pretest to 3.53 and 3.36 in the middle test and the posttest respectively. Similarly, the mean scores of comprehensibility changed from 3.40 in the pretest to 3.36 in the middle test and 3.20 in the posttest. It seems the participants received some degrees of improvement both after being taught by the NST and the NNST. Nevertheless, statistic analysis results from repeated-measures ANOVA indicate, the participants' improvement from the pretest to the middle test was statistically non-significant (accentedness: $F(1,59)=0.365, p=0.548$; comprehensibility: $F(1,59)=0.130, p=0.720)$. Their degree of improvement from the middle test to the posttest, however, was also revealed to be statistically significant (accentedness: $F(1,59)=4.941, \quad p=0.009$; comprehensibility: $F(1,59)=4.308, p=0.013)$. Moreover, gender difference was revealed to be non-significant for the participants' degree of accentedness $(F(1,29)=0.10, p=0.75)$ and comprehensibility $(F(1,29)=0.37, p=0.55)$. 
Table 2. Descriptive data of the participants' accentedness and comprehensibility in the semi-schemed interview in the 3 tests

\begin{tabular}{lllllll}
\hline & \multicolumn{3}{l}{ Accentedness } & \multicolumn{4}{l}{ Comprehensibility } \\
\hline \multirow{3}{*}{ N } & Pretest & Middle test & Posttest & Pretest & Middle test & Posttest \\
Mean & 30 & 30 & 30 & 30 & 30 & 30 \\
Std. Deviation & 3.65 & 3.64 & 3.51 & 3.49 & 3.48 & 3.36 \\
Minimum & 0.41 & 0.40 & 0.42 & 0.43 & 0.42 & 0.43 \\
Maximum & 2.77 & 2.68 & 2.61 & 2.38 & 2.28 & 2.09 \\
\hline
\end{tabular}

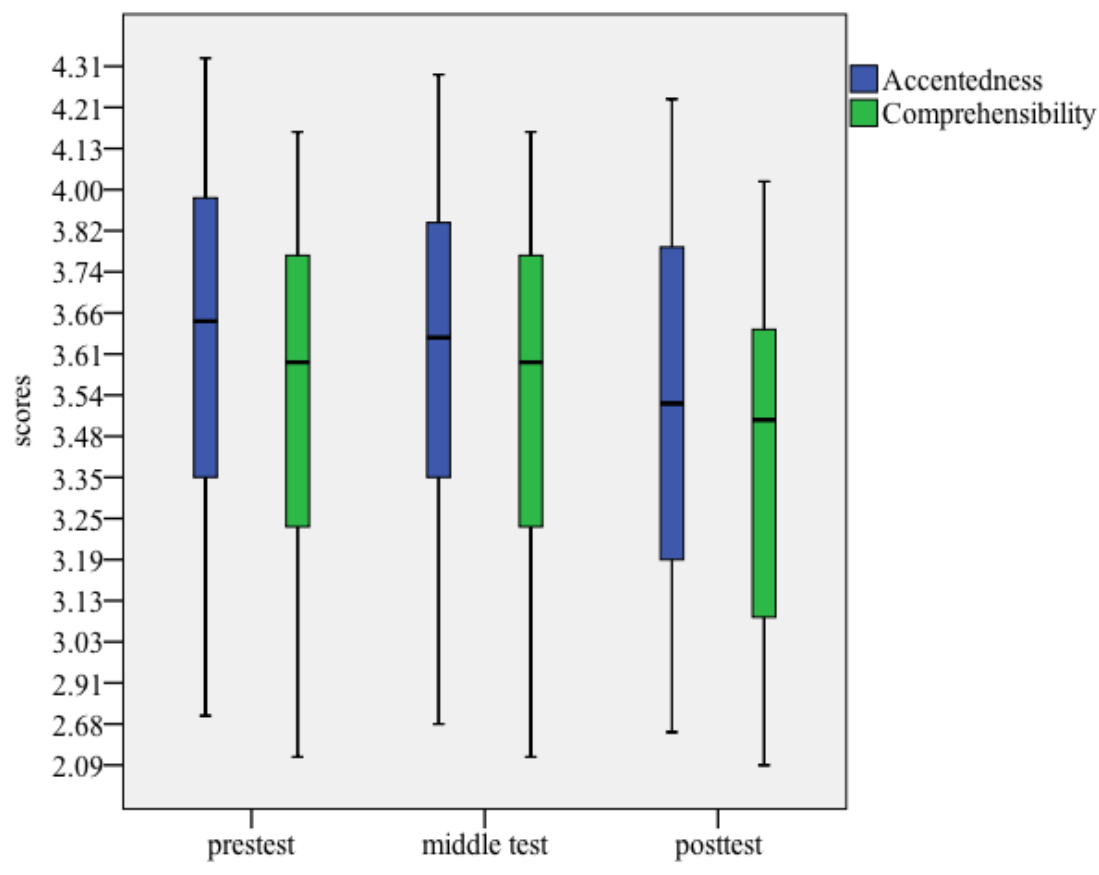

Figure 2. Boxplots of the participants' accentedness and comprehensibility in the semi-schemed interview in the 3 tests

Table 2 and Figure 2 describe the participants' performance in the semi-schemed interview. Similar to that in the read aloud task, the participants showed linear improvement from pretest to posttest both in the aspects of accentedness and comprehensibility. According to the mean scores shown in Table 2, it seems the participants received a higher degree of improvement in the posttest than that in the middle test both for accentedness and comprehensibility. Statistic analysis from One-way ANOVA indicate, from the pretest to the middle test, the participants' improved degrees of accentedness and comprehensibility were both statistically non-significant (accentedness: $F(1,59)=0.016, p=0.899$; comprehensibility: $F(1,59)=0.070, p=0.792)$. However, their degrees of improvement from the middle test to the posttest were also revealed to be statistically significant (accentedness: $F(1,59)=4.379, p=0.024$; comprehensibility: $F(1,59)=4.056, p=0.031)$.

So far, the first research question could be answered with the results shown above. That is, the participants received some degrees of improvement in the aspects of accentedness and comprehensibility both after being taught by the NST and the NNST. Nevertheless, their improvement was statistically non-significant after being taught by the NST, but was statistically significant after being taught by the NNST.

This finding was unexpected, as many previous studies found that NSTs and NNSTs are both successful in L2 pronunciation teaching (Brutt-Griffler \& Samimy, 1999). Levis et al. (2016), for instance, found that the 
teachers' native language background did not display a significant effect on the participants' degree of improvement in accentedness or comprehensibility. The participants neither received a significant overall improvement in their comprehensibility or accentedness in both the NST and the NNST's class. The discrepancy between the finding in Levis et al. (2016) and the present study may be attributed to the differences of the teaching classes. In Levis et al. (2016), the students in the NST and the NNST's class experienced almost the same teaching procedure, teaching materials, classroom activities, etc. In the present study, however, the participants were taught by the NST first and then experienced the NNST's class. The teaching materials, procedures, and classroom activities were different between the two phases. There must be some difference concerning the NST and the NNST's teaching styles. It was possible that the participants benefited more from the NNST's class was because they were more used to the NNST's teaching style. It was also possible that due to the participants' English proficiency level was intermediate, and NST could not speak Chinese, they might have some difficulties with the understanding of the NST's instructions, thus resulted in their non-significant overall improvement after being taught by the NST. Moreover, the NNST's accentedness and comprehensibility rated to be high, which may have contributed to the participants' significant improvement. On the whole, this finding is in favor of NNSTs in L2 pronunciation teaching.

\subsection{Findings from the Questionnaire}

Table 3. The participants' evaluation of the teachers and the classes (partially adopted from Levis et al., 2016)

\begin{tabular}{lll}
\hline Overall ratings (1=very good; 5=very poor) & NST & NNST \\
\hline Overall rating of the teacher & 1.71 & 1.69 \\
Overall rating of the class & 1.68 & 1.70 \\
\hline Ratings of the teachers' teaching (1=strongly agree; 5=strongly disagree) & $\mathrm{NST}$ & $\mathrm{NNST}$ \\
\hline The teacher was well-prepared for the class. & 1.42 & 1.36 \\
The teacher presented the subject matter effectively. & 1.92 & 1.84 \\
The teacher appeared to enjoy teaching. & 1.53 & 1.55 \\
I am glad I had the opportunity to study with the teacher & 1.61 & 1.64 \\
\hline Evaluation of the teachers' personality & $\mathrm{NST}$ & $\mathrm{NNST}$ \\
\hline Friendliness (1=unfriendly; 5=very friendly) & 4.66 & 4.72 \\
Being reserved or not (1=reserved; 5=energetic) & 4.35 & 4.27 \\
Enthusiasm (1=boring; 5=enthusiastic) & 4.71 & 4.74 \\
Being approachable or not (1=distant; 5=approachable) & 4.22 & 4.30 \\
Being organized or not (1=disorganized; 5=organized) & 4.68 & 4.74 \\
\hline In general, do you prefer to be taught be a NST & $\mathrm{n}=21$ & $\mathrm{n}=9$ \\
or a NNST for English pronunciation? & $(70 \%)$ & $(30 \%)$ \\
\hline
\end{tabular}

Table 3 above answers the second research question. According to the data collected from the questionnaire, the participants' ratings of the 2 teachers and their classes were similar. This finding is in line with that Brutt-Griffler and Samimy's (1999). That is, both the NST and the NNST' teaching was perceived to be successful. In the final decision, however, the majority of the participants $(70 \%)$ prefer to be taught by a NST for English pronunciation rather than a NNST (30\%), even though they had gained better progress in accentedness and comprehensibility with the NNST than with the NST (see section 3.1 above). It is in support of the assumption in Moussu \& Llurda, (2008) - students might display more positive attitudes toward teachers with a native accent, though they do not necessarily have negative attitudes toward teachers with a non-native accent. Moreover, this finding is in accordance with that in Levis et al., (2016). An interesting thing is, in Levis et al., (2016), the Turkish teacher showed a high rating of foreign accent, which could have been easily perceived by the students. The Chinese teacher in the present study, however, displayed native-like American English accent. Still, the majority of the participants preferred to have NST for English pronunciation teaching. To further examine this issue, the investigator personally asked some of the participants regarding their preferences after the data was collected.

The majority of the 21 participants who chose NST over NNST said that they felt a NST could be a better model 
of English pronunciation than a NNST. Others said they did not have many chances to speak to native English speakers. Being taught by a NST would be a good chance to be exposed to the target language. This point of view is similar to that was discussed in Levis et al., (2016). That is, the participants seemed to think that they could "catch" the native accent by being taught by a NST. This view was revealed to be mistaken by the findings of the present study - the participants did not gain significant improvement after being taught by a NST. Similar findings are available in some previous studies (Levis et al., 2016; LeVelle \& Levis, 2014; Levis, 2015).

As for the rest of the 9 participants who preferred to be taught by a NNST, they reported that having a NST's class made them uncomfortable sometimes, although they rated the NST to be quite friendly. They could not explain exactly what made them feel uncomfortable. Yet, three of the participants' answers may shed some light on this point.

Answer one: "I feel she is different from us. I mean, she looks different from us, not in a bad way, just different you know. I'm (was) not sure if I can (could) understand her teaching, because she is a foreigner. Maybe she can't speak a single Chinese word. My English is not good. I'm very worried...hm...I cannot communicate with her."

Answer two: "Sometimes I feel nervous at the teacher's (the NST) class. She... her teaching is...was too active. I mean, we need to answer her questions or take part in different activities all the time. I like learning by myself, not so many activities (Note 2)."

Answer three: "I prefer a NNST, because a NNST can understand me when my words (expression) are not correct. S/he can teach me how to pronounce a word in Chinese (S/he can give instructions in Chinese), so I can understand her/him."

The first answer may have shown the significance of a pronunciation teacher's physical appearance of nativeness in teaching. Generally, students may prefer a teacher with native-like physical appearance to teach the pronunciation of a target language (Braine, 2005; Golombek \& Jordan, 2005). In the present study, however, it seems the NST's nativeness did not give her extra credit. It might be attributed to the participant's own English proficiency level, or be more precisely, her own perception of her English proficiency level. She used "not good" to describe her English level, despite that all the participants displayed intermediate level in the Oxford Quick Placement test.

The second answer displayed the differences between NST and NNST's teaching styles. Traditional teaching in China is teacher centered, thus does not involve many communicative classroom activities. Being taught in this way for many years, some students may not be used to the NST's teaching style, which could be "too active" for them. According to the NST and NNST's reports, both of them employed pair work, group work, and whole-class activities in the class. However, the NNST reported to have used about half of the time for instruction, thus left about half of the time for classroom activities. The NST, however, only used about $1 / 3$ of time for instruction, and left about $2 / 3$ of the time for various kinds of classroom activities. This may have resulted in the participant's nervousness in the NST's class. As mentioned Lasagabaster \& Sierra (2002), teaching style plays a significant role in the students' preference of NST or NNST. At this point, we may also assume that those who chose NST over NNST may be used to, or even fond of the NST's teaching style.

In regard to the third answer, it seems the participant was not confident in his English proficiency level. He thought instruction in Chinese could be more helpful than in English. As mentioned in section 1.2, the participants' L2 proficiency level plays a critical role in their preferences for a NST or a NNST (Madrid \& Canado, 2004; Lasagabaster \& Sierra, 2002). At this point, it seems the participant's own perception of their L2 proficiency level is also significant factor concerning their preferences on teachers. We may speculate that if the participant was more confident at his English proficiency level, he might not be worried about being unable to be understood by the NST.

\section{Conclusion}

The present study investigated L2 learners' preferences of NST and NNST as their English pronunciation teacher, and compared the participants' accentedness and comprehensibility in L2-English pronunciation after being taught by a NST and a NNST. According to the overall results, the majority of them prefer having a NST as their pronunciation teacher. The testing results, however, indicated that the participants received significant improvement after being taught by the NNST, but non-significant improvement after being taught by the NST. Possible reasons for the participants' preferences were analyzed, such as the participants' mistaken views on L2 pronunciation learning, their own L2 proficiency level, etc. Findings of the present study may have provided supporting evidence regarding NNSTs' suitability in L2 pronunciation teaching. 


\section{References}

Bloomfield, L. (1993). Language. New York: Holt Rinehart Winston.

Braine, G. (2005). A history of research on non-native speaker English teachers. In E. Llurda (Ed.), Non-native language teachers: Perceptions, challenges, and contributions to the profession (pp. 13-23). New York, NY: Springer. http://dx.doi.org/10.1007/0-387-24565-0_2

Chomsky. (1965). Aspects of the theory of syntax. MIT Press, Cambridge.

Chen, X. (2008). A survey: Chinese college students' perceptions of non-native English teachers. CELEA Journal, 31(3), 75-82.

Brutt-Griffler, J., \& Samimy, K. K. (1999). Revisiting the Colonial in the Postcolonial: Critical Praxis for Nonnative - English - Speaking Teachers in a TESOL Program. Tesol Quarterly, 33(3), 413-431. http://dx.doi.org/10.2307/3587672

Davies, A. (1991). The native speaker in applied linguistics. Edinburgh: Edinburgh University Press.

Felix, S. (1987). Cognition and language growth. Dordrecht, Netherlands: Foris.

Golombek, P., \& Jordan, S. (2005). Becoming "black lambs" not "parrots": A post- structuralist orientation to intelligibility and identity. TESOL Quarterly, 39, 513-533. http://dx.doi.org/10.2307/3588492

Gurkan, S., \& Yuksel, D. (2012). Evaluating the contributions of native and non- native teachers to an English Language Teaching Program. Procedia-Social and Behavioral Sciences, 46, 2951-2958. http://dx.doi.org/10.1016/j.sbspro.2012.05.596

Hazan, V., Sennema, A., Iba, M., \& Faulkner, A. (2005). Effect of audiovisual perceptual training on the perception and production of consonants by Japanese learners of English. Speech communication, 47(3), 360-378. http://dx.doi.org/10.1016/j.specom.2005.04.007

Hughes, A., \& Lascaratou, C. (1982). Competing criteria for error gravity. English Language Teaching Journal, 36, 175-182. http://dx.doi.org/10.1093/elt/36.3.175

Lasagabaster, D., \& Sierra, J. M. (2002). University students' perceptions of native and non-native speaker teachers of English. Language Awareness, 11(2), 132-142. http://dx.doi.org/10.1080/09658410208667051

Lee, J. J. (2005). The native speaker: An achievable model? Asian EFL Journal, 7(2), 152-163.

LeVelle, K., \& Levis, J. (2014). Understanding the impact of social factors on L2 pro- nunciation: Insights from learners. In J. Levis, \& A. Moyer (Eds.), Social dynamics in second language accent (pp. 97-118). Berlin, Germany: Walter de Gruyter. http://dx.doi.org/10.1515/9781614511762.97

Levis, J. (2015). Learners' views of social issues in pronunciation learning. Journal of Academic Language and Learning, 9(1), A42-A55.

Levis, J. M., Sonsaat, S., Link, S., \& Barriuso, T. A. (2016). Native and Nonnative Teachers of L2 Pronunciation: Effects on Learner Performance. TESOL Quarterly. http://dx.doi.org/10.1002/tesq.272

Ma, L. (2012). Advantages and disadvantages of native- and nonnative-English- speaking teachers: Student perceptions in Hong Kong. TESOL Quarterly, 46, 280-305. http://dx.doi.org/10.1002/tesq.21

Madrid, D., \& Canado, M. L. P. (2004). Teacher and student preferences of native and nonnative foreign language teachers. Porta Linguarum, 2, 125-138.

Mahboob, A. (2004). Native or nonnative: What do the students think? In L. D. Kamhi-Stein (Ed.), Learning and teaching experience: Perspectives on nonnative English-speaking professionals (pp. 121-147). Ann Arbor: University of Michigan Press.

Medgyes, P. (1994). The Non-Native Teacher. London: Macmillan.

Medgyes, P. (2001). When the teacher is a non-native speaker. Teaching English as a second or foreign language, $3,429-442$.

Moussu, L. (2006). Native and non-native English-speaking as a second language teach-ers: Student attitudes, teacher self-perceptions, and intensive English program administrator beliefs and practices. Unpublished doctoral dissertation, Purdue University, West Lafayette, IN.

Moussu, L., \& Llurda, E. (2008). Non-native English-speaking English language teachers: History and research. Language Teaching, 41, 315-348. http://dx.doi.org/10.1017/S0261444808005028 
Munro, M., \& Derwing, T. (2006). The functional load principle in ESL pronunciation instruction: An exploratory study. System, 34, 520-531. http://dx.doi.org/10.1016/j.system.2006.09.004

Piller, I. (2002). Passing for a native speaker: Identity and success in second language learning. Journal of Sociolinguistics, 6(2), 179-208. http://dx.doi.org/10.1111/1467-9481.00184

Rao, Z. (2008). Reflecting on native-English-speaking teachers in China. Essential Teacher, 5(1), 23-25.

Reves, T., \& Medgyes, P. (1994). The non-native English speaking EFL/ESL teacher's self-image: An international survey. System, 22, 353-367. http://dx.doi.org/10.1016/0346-251X(94)90021-3

\section{Notes}

Note 1. The NST and NNST were asked to read an English passage (about 100 words) and were auditorily recorded. The accentedness and comprehensibility of their reading was rated by the 3 raters mentioned above with a 5-likert scale. The results were the average of the raters' evaluations.

Note 2. The participant then explained in Chinese: she prefers to learn passively, whereas the NST had too many interactive classroom activities, which made him nervous.

\section{Copyrights}

Copyright for this article is retained by the author(s), with first publication rights granted to the journal.

This is an open-access article distributed under the terms and conditions of the Creative Commons Attribution license (http://creativecommons.org/licenses/by/4.0/). 